Available online on 15.01 .2019 at http://jddtonline.info
(C) 2011-18, publisher and licensee JDDT, This is an Open Access article which permits unrestricted
non-commercial use, provided the original work is properly cited

Open $\sigma_{\text {Access }}$

Research Article

\title{
Design, formulation and evaluation of sustained release bilayer tablets of ciprofloxacin hydrochloride
}

\author{
Kar Ayan Kumar*1, Majumder Tandrima², Majumdar Subhabrota1, Mahanti Beduin ${ }^{3}$, Kar Banhishikha', \\ Chakraborty Satyam4, Parya Hiranmoy ${ }^{1}$, Saha Surajit ${ }^{4}$ \\ ${ }^{1}$ Department of Pharmaceutics, Calcutta Institute of Pharmaceutical Technology \& AHS, Banitabla, Uluberia, Howrah-711316, West Bengal. \\ ${ }^{2}$ Dhanvanthri College of Pharmaceutical Sciences, Thirumala hills- 509001, Mahbubnagar. \\ ${ }^{3}$ School of Pharmacy, Techno India University, Salt Lake, West Bengal. \\ ${ }^{4}$ Himalayan Pharmacy Institute, Majitar, East Sikkim.
}

\begin{abstract}
The present research work involve the development of a bilayer tablet of ciprofloxacin hydrochloride using a superdisintegranting agent (sodium starch glycolate) for the fast releasing layer and hydrophobic polymers like ethyl cellulose, acrycoat L100 and acrycoat S100 for the delayed releasing layer. Ciprofloxacin was used as a model drug. Tablets were prepared by wet granulation method. The prepared bilayer tablets were evaluated for angle of repose, bulk density, tapped density, Carr's index, Hausner's ratio at the precompression stage and thickness variation, weight variation, hardness, friability, drug content, disintegration time, in vitro drug release study at the post compression stage.. In vitro dissolution studies were carried out in a USP 24 apparatus I. In vitro dissolution kinetics followed the Higuchi model via a non-Fickian diffusion controlled release mechanism after the initial burst release. FT-IR studies revealed that there was no interaction between the drug and polymers. Statistical analysis (ANOVA) showed no significant difference in the cumulative amount of drug release after 15 min, but significant difference $(p<0.05)$ in the amount of drug released after $12 \mathrm{~h}$ from optimized formulations was observed. Present research work involves the development of a bilayer tablet of ciprofloxacin hydrochloride using a superdisintegrant for the fast releasing layer and hydrophobic polymers for the delayed releasing layer. There was the initial burst effect from the formulations to provide the loading dose of the drug, followed by sustained release to provide maintenance dose of the drug.
\end{abstract}

Keywords: Superdisintegrants, Burst release, Wet granulation, non-Fickian, Sustained release

Article Info: Received 10 Nov 2018; $\quad$ Review Completed 20 Dec 2018; $\quad$ Accepted 21 Dec 2018; Available online 15 Jan 2019

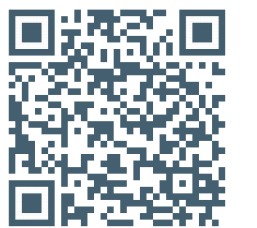

Cite this article as:

Kar AK, Majumder T, Majumdar S, Mahanti B, Kar B, Chakraborty S, Parya H, Saha S, Design, formulation and evaluation of sustained release bilayer tablets of ciprofloxacin hydrochloride, Journal of Drug Delivery and Therapeutics. 2019; 9(1):4653 DOI: http://dx.doi.org/10.22270/jddt.v9i1.2158

*Address for Correspondence:

Ayan Kumar Kar, Department of Pharmaceutics, Calcutta Institute of Pharmaceutical Technology \& AHS, Banitabla, Uluberia, Howrah-711316, West Bengal.

\section{INTRODUCTION}

The goal of any drug delivery system is to provide a therapeutic amount of the drug to the proper site in the body to achieve promptly, and then maintain, the desired drug concentration ${ }^{1}$. The idealized objective points important to the drug delivery, namely, spatial placement and temporal delivery of a drug. Spatial placement relates to targeting a drug to a specific organ or tissue, while temporal delivery refers to the controlling the rate of drug delivery to the target tissue. The multilayered tablet concept has been long utilized to develop sustained release formulations. Such a tablet has a fast releasing layer and may contain bi- or triple layers to sustain the drug release. The pharmacokinetic advantage relies on the fact that drug release from fast releasing granules leads to a sudden rise in the blood concentration. However, the blood level is maintained at ISSN: 2250-1177 steady state as the drug is released from the sustaining granules ${ }^{2}$. Two layer tablets may be designed for sustained release one layer for the immediate release of the drug and second layer for extended release thus maintaining a prolonged blood level. The weight of each layer can be accurately controlled in contrast to putting one drug of a combination product in a sugar coating. Bi-layer tablets are novel drug delivery systems where combination of two or more drugs in a single unit having different release profiles which improves patient compliance, prolongs the drug(s) action, avoid saw tooth kinetics resulting in effective therapy along with better control of plasma drug levels. Bi-layer tablets are very common for drugs such as captopril, metoprolol, amoxicillin and potassium clavulanate, propranolol hydrochloride, bambuterol hydrochloride etc 3 . In the present study ciprofloxacin was used as a model drug. 
Ciprofloxacin is a broad-spectrum antibiotic belongs to a group called fluoroquinolones that is active against both Gram-positive and Gram-negative bacteria. It functions by inhibiting DNA gyrase, a type II topoisomerase, which is an enzyme necessary to separate replicated DNA, thereby inhibiting cell division. Ciprofloxacin is rapidly absorbed orally, but food delay absorption and first pass effect occurs. The most prominent feature of ciprofloxacin is high tissue penetrability: concentration in lung, sputum, muscle, bone, prostate and phagocytes exceed that in plasma, but CSF and aqueous levels are lower. It excreted primarily in urine, both by glomerular filtration and tubular secretion, urinary and biliary concentration is 10 to 50 fold higher than plasma. Hence In comparison with the single sustain layer tablet, a double layer containing one immediate release compartment and one sustain release layer offers advantages ${ }^{4}$. The objective of the proposed work is to formulate a bi-layer tablet which can control the release time after oral administration, at a particular site and sustain the release of drug. This is especially useful for achieving controlled plasma level as well as improving bioavailability. Bi-layer drug shall be prepared using wet granulation method or may be by dry granulation techniques and study shall be employed to finalize the method for the preparation, on the basis of several physicochemical parameters. Final dosage form will be optimized statistically and shall be evaluated and optimized.

\section{MATERIALS AND METHOD}

Materials: The Ciprofloxacin hydrochloride was a gift sample by the Zydus Cadila, Baghekhola, East Sikkim. Acryl coat L-100 and Acryl coat S-100 was obtained from Corel Pharmachem, Ahmadabad. Ethyl cellulose, Lactose, Starch powder, Talcum powder, Microcrystalline cellulose, Magnesium stearate were purchased from S.D.Fine - Chem. Limited, Mumbai. Sodium starch glycolate, Ethyl alcohol was purchased from Lobachemie, Pvt ltd .Mumbai. Tartrazine (tatar yellow) was obtained from Burgoyne Burbidge's\& co. Mumbai.

\section{Methodology:}

\section{Formulation of the fast release layer:}

The dose for the fast releasing layer and the delayed releasing layer of the tablets were calculated individually5. The fast release granules were prepared by wet granulation technique by blending the drug uniformly with sodium starch glycolate using starch paste $(10 \% \mathrm{~m} / \mathrm{m})$ as binder as per the formulae given in Table 1 . The cohesive mass obtained was passed through a $1000 \mu \mathrm{m}$ sieve, dried at $60^{\circ} \mathrm{C}$ for 1 hour. The granules were again passed through a $1000 \mu$ mscreen to break up agglomerates. The granules were then mixed with talc and magnesium stearate.

Table 1: Composition of sustained releasing layer

\begin{tabular}{|c|c|c|c|c|c|c|c|c|c|c|}
\hline \multirow{2}{*}{ Sl. no. } & \multirow{2}{*}{$\begin{array}{c}\text { Ingredients } \\
\text { (quantity/tablets) in mg }\end{array}$} & \multicolumn{9}{|c|}{ Batch code } \\
\hline & & F1 & F2 & F3 & F4 & F5 & F6 & F7 & F8 & F9 \\
\hline 1 & $\begin{array}{l}\text { Ciprofloxacin } \\
\text { Hydrochloride }\end{array}$ & 170 & 170 & 170 & 170 & 170 & 170 & 170 & 170 & 170 \\
\hline 2 & Ethyl cellulose & 85 & 170 & 255 & $\ldots$ & $\ldots$ & $\ldots$ & $\ldots$ & $\ldots$ & $\ldots$ \\
\hline 3 & Acrycoat L100 & $\ldots$ & $\ldots$ & $\ldots$ & 85 & 170 & 255 & $\ldots$ & $\ldots$ & $\ldots$ \\
\hline 4 & Acrycoat S100 & $\ldots$ & $\ldots$ & $\ldots$ & $\ldots$ & $\ldots$ & $\ldots$ & 85 & 170 & 255 \\
\hline 5 & Lactose & 190 & 105 & 20 & 190 & 105 & 20 & 190 & 105 & 20 \\
\hline 6 & Starch paste10\% & 40 & 40 & 40 & 40 & 40 & 40 & 40 & 40 & 40 \\
\hline 7 & Talc & 6 & 6 & 6 & 6 & 6 & 6 & 6 & 6 & 6 \\
\hline 8 & Magnesium stearate & 4 & 4 & 4 & 4 & 4 & 4 & 4 & 4 & 4 \\
\hline
\end{tabular}

\section{Formulation of the sustained release layer:}

The granules for sustaining layer of the tablets were also formulated by the wet granulation technique by mixing the drug individually with the polymer (acrycoat S100, ethyl cellulose and acrycoat L100) uniformly followed by lactose ${ }^{6}$. Starch paste $(10 \% \mathrm{~m} / \mathrm{m})$ was incorporated as binder in the formulations (Table 2). The sustaining granules were also subjected to similar processing steps as the fast releasing granules.

Table 2: Composition of fast releasing layer

\begin{tabular}{|c|c|c|}
\hline Sl.no. & Ingredients (quantity/tablets) in mg & Quantity for a single tablet in mg \\
\hline 1. & Ciprofloxacin Hydrochloride & 80 \\
\hline 2. & Sodium starch glycolate & 8 \\
\hline 4. & Starch paste (10\%) & 25 \\
\hline 5. & Talcum powder & 2 \\
\hline 6. & Magnesium stearate & 1 \\
\hline
\end{tabular}

\section{Preformulation Studies}

The preformulation studies like angle of repose, bulk density, tapped density3, 7. Compressibility or Carr's index drug excipients compatibility studies, Hausner's ratio ${ }^{8}$ were evaluated which was shown in table 3 .

\section{Compression of Bilayer tablets:}

The granules for the sustained release layer was compressed lightly using a single punch-tableting machine (Rimek Mini
Press 1,Shakti Engineering Ltd, India) equipped with $6.5 \mathrm{~mm}$ round, flat and plain punches. Over this compressed layer, the required quantity of granules for the fast release layer were placed and compressed again to obtain the hardness of the resultant tablets in the range of $5-7 \mathrm{~kg} \mathrm{~cm}^{-2}$.

\section{Physical tests for Bilayer tablets ${ }^{\text {9-11 }}$}

Standard physical tests for the bilayer matrix tablets were performed and average values were calculated. 20 tablets were individually weighed and then their average weight 
was calculated. The average weight was compared with the individual tablet weights and the weight variation was calculated. The hardness of the prepared tablets was determined by using Monsanto tablet hardness tester (Royal Scientific Pvt. Ltd, Chennai). Twenty tablets were weighted again, introduced into the plastic chamber of the friability apparatus (Electrolab, Mumbai), The apparatus was operated for 4 minutes at $25 \mathrm{rpm}$. These tablets were then again weighed and percentage loss in weight was calculated.

\section{Determination of drug content in tablets:}

Three tablets from each batch were selected randomly and transferred to $100 \mathrm{ml}$ volumetric flasks which were filled up with $0.1(\mathrm{~N})$ hydrochloric acid of $\mathrm{pH} 1.2$ kept it for 24 hours, then took $1 \mathrm{ml}$ from each of volumetric flask and was transferred to the test tubes. Samples were then filtered, suitably diluted and analyzed spectrophotometrically at a wavelength of $277.5 \mathrm{~nm}$ which is given in table 4 .

\section{Determination of in-vitro dissolution study:}

Dissolution study was carried out in USP -II type dissolution apparatus (paddle type) in TDT 08L model (Electrolab, Kolkata). Dissolution study was performed at $50 \mathrm{rpm}$ in $900 \mathrm{ml}$ of simulated gastric fluid of $\mathrm{pH} 1.2$ for the first 2 hours and followed by simulated intestinal fluid of $\mathrm{pH} 6.8$ phosphate buffer for the remaining hours. The temperature was maintained at $37 \pm 0.2^{\circ} \mathrm{C}$. $5 \mathrm{ml}$ of sample was withdrawn at a predetermined interval and the volume of dissolution medium was maintained by adding same volume of dissolution medium each time. Then the sample was filtered through Whatmann filter paper. The absorbance of withdrawn sample was measured spectrophotometrically at $277.5 \mathrm{~nm}$ after suitable dilution and the corresponding concentration was determined from the respective calibration curve.

\section{Statistical Analysis (One-way Analysis of Variance or ANOVA) 12:}

In-vitro drug release data from the optimized bilayer tablet formulations were subjected to the analysis of variance
(ANOVA) at two different time intervals, likely at the first 15 minutes and at the $10^{\text {th }}$ hour using Graph pad Instat software version 3.10. For in-vitro dissolution testing at the first 15 minute, each formulation was subjected three times and the percentage cumulative drug release was calculated shown in table 5. For in-vitro dissolution testing at the $10^{\text {th }}$ hour, each formulation was subjected three times and the percentage cumulative drug release was calculated shown in table 8 . Then the data of three optimized formulations were subjected to one way ANOVA analysis using Tukey testing-all column comparison test which was shown in table 9.

\section{Drug-polymer compatibility study using FT-IR spectrophotometer ${ }^{11}$ :}

FT-IR study was carried out to identify any possible drugpolymer interaction. The peaks of pure drug and pure individual polymers were compared to the mixtures of the same and any significant shifting of the band was noted as the sign of interaction which is shown in Figure.

\section{RESULT AND DISCUSSSION}

In this preformulation study, prepared granules were evaluated for various physical properties shown in table 3 . The bulk densities for the granules of various formulations ranged between $0.502 \pm 0.654 \mathrm{gm} / \mathrm{ml}$ and $0.598 \pm 0.061$ $\mathbf{g m} / \mathbf{m l}$, as determined by the tapped density method. This value of bulk density indicates of good packing character. The compressibility index (Carr's index) for all the formulations was found to be almost below $17 \%$, indicating desirable flow properties. The flow properties of the granules were further analyzed by determining the angle of repose for all granules; it ranged between 19.66․0.538 and 26.75\% $\mathbf{0 . 7 3 5 \%}$. The value indicates good flow properties of granules with ethyl cellulose, acrycoatL100 and acrycoat S100 as matrix material. Hausner's ratio also calculated for the granules flow property determination and seems to be within the suitable range i.e.; below 2.5. The results of the preformulation study of drug and the physicochemical properties of the prepared tablets are given in table 4 accordingly.

Table 3: Results of the evaluations conducted at preformulation stages

\begin{tabular}{|c|c|c|c|c|c|}
\hline $\begin{array}{c}\text { Batch } \\
\text { no. }\end{array}$ & $\begin{array}{c}\text { Angle of repose } \\
\mathbf{( \mathbf { 9 }}\end{array}$ & $\begin{array}{c}\text { Bulk density } \\
\mathbf{( g m / \mathbf { m l } )}\end{array}$ & $\begin{array}{c}\text { Tapped density } \\
\mathbf{( g m / \mathbf { m } )}\end{array}$ & $\begin{array}{c}\text { Carr's index } \\
\mathbf{0}\end{array}$ & Hausner's Ratio \\
\hline F1 & $25.33 \pm 0.363$ & $0.551 \pm 0.0821$ & $0.665 \pm 0.894$ & $14.01 \pm 0.509$ & 1.206 \\
\hline F2 & $24.23 \pm 0.259$ & $0.521 \pm 0.0534$ & $0.581 \pm 0.941$ & $13.014 \pm 0.331$ & 1.115 \\
\hline F3 & $22.12 \pm 0.244$ & $0.582 \pm 0.758$ & $0.641 \pm 0.290$ & $11.34 \pm 0.162$ & 1.1013 \\
\hline F4 & $26.75 \pm 0.735$ & $0.574 \pm 0.3115$ & $0.673 \pm 0.533$ & $17.31 \pm 0.649$ & 1.1724 \\
\hline F5 & $24.46 \pm 0.338$ & $0.511 \pm 0.341$ & $0.593 \pm 0.734$ & $14.05 \pm 0.947$ & 1.1604 \\
\hline F6 & $21.39 \pm 0.567$ & $0.502 \pm 0.654$ & $0.598 \pm 0.318$ & $14.349 \pm 0.845$ & 1.1912 \\
\hline F7 & $25.08 \pm 0.198$ & $0.598 \pm 0.061$ & $0.657 \pm 0.431$ & $16.14 \pm 0.068$ & 1.0986 \\
\hline F8 & $22.7 \pm 0.933$ & $0.524 \pm 0.141$ & $0.593 \pm 0.334$ & $13.31 \pm 0.649$ & 1.1316 \\
\hline F9 & $19.66 \pm 0.538$ & $0.555 \pm 0.304$ & $0.598 \pm 0.018$ & $11.5 \pm 0.947$ & 1.0774 \\
\hline
\end{tabular}

During preformulation study, FT-IR (Fourier Transform Infrared) spectrophotometer was used to determine the compatibility in between drug and polymers and with excipient. Study was carried out for the pure drug (Ciprofloxacin hydrochloride) alone and in combination with polymers (Ethyl cellulose, Acrycoat S100 and Acrycoat L100) and excipient (Sodium starch glycolate) under study shown in figure 1 to figure 4 . Major frequencies of functional groups of pure drug remained unchanged in presence of polymer. Hence, it seems that there is no major interaction between the drug and the polymers used in the study. 
Table 4: Results of studies conducted for physico-chemical characteristics of the prepared tablet

\begin{tabular}{|c|c|c|c|c|c|c|}
\hline Formulation & $\begin{array}{l}\text { Thickness } \\
\text { variation }(\mathrm{cm})\end{array}$ & $\begin{array}{l}\text { Weight } \\
\text { variation }\end{array}$ & $\begin{array}{l}\text { Hardness } \\
\left(\mathrm{Kg} / \mathrm{cm}^{2}\right)\end{array}$ & $\begin{array}{l}\text { Friability } \\
(\%)\end{array}$ & $\begin{array}{l}\text { Disintegration } \\
\text { Time (hrs) }\end{array}$ & $\begin{array}{c}\text { Drug content } \\
(\%)\end{array}$ \\
\hline F1 & $0.41 \pm 0.03$ & $609 \pm 3.8$ & $5.5 \pm 0.8$ & 0.9 & $5.05 \pm 0.065$ & $101 \pm 1.34$ \\
\hline F2 & $0.40 \pm 0.02$ & $611 \pm 2.92$ & $6.1 \pm 0.5$ & 0.88 & $7.21 \pm 0.031$ & $98 \pm 2.31$ \\
\hline F3 & $0.39 \pm 0.02$ & $608 \pm 4.4$ & $6.0 \pm 0.3$ & 0.78 & $7.35 \pm 0.016$ & $99 \pm 3.56$ \\
\hline $\mathrm{F} 4$ & $0.41 \pm 0.06$ & $609 \pm 2.21$ & $6.3 \pm .0 .7$ & 0.91 & $5.50 \pm 0.07$ & $100 \pm 2.21$ \\
\hline F5 & $0.39 \pm 0.04$ & $610 \pm 3.78$ & $5.4 \pm 0.8$ & 0.814 & $6.05 \pm 0.051$ & $102 \pm 1.45$ \\
\hline F6 & $0.40 \pm 0.05$ & $608 \pm 4.89$ & $5.2 \pm 0.4$ & 0.71 & $6.40 \pm 0.042$ & $99 \pm 3.12$ \\
\hline F7 & $0.41 \pm 0.04$ & $612 \pm 3.76$ & $5.6 \pm 0.2$ & 0.962 & $5.49 \pm 0.071$ & $102 \pm 2.65$ \\
\hline F8 & $0.41 \pm 0.03$ & $608 \pm 3.18$ & $5.8 \pm 0.7$ & 0.76 & $6.40 \pm 0.049$ & $101 \pm 2.12$ \\
\hline F9 & $0.40 \pm 0.02$ & $611 \pm 4.98$ & $6.0 \pm 0.5$ & 0.67 & $7.140 \pm 0.044$ & $98 \pm 2.32$ \\
\hline
\end{tabular}

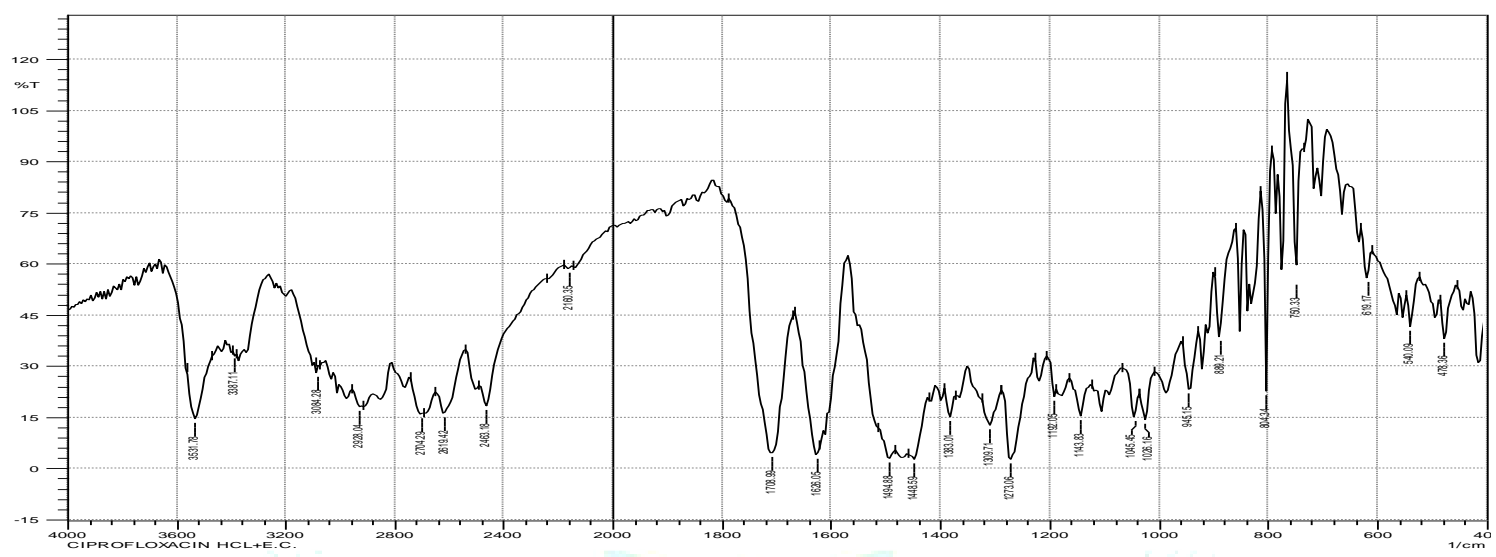

Figure 1: FTIR-Spectra of Ciprofloxacin hydrochloride with Ethyl cellulose

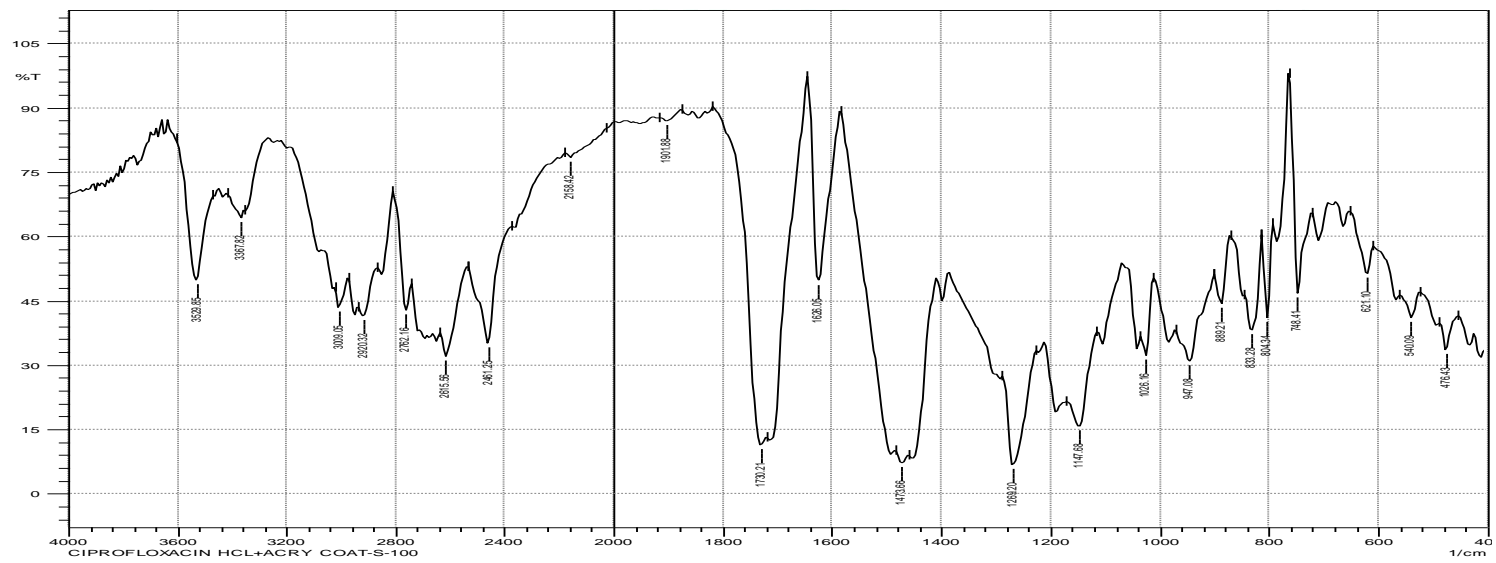

Figure 2: FTIR-Spectra of Ciprofloxacin hydrochloride with Acrycoat S100

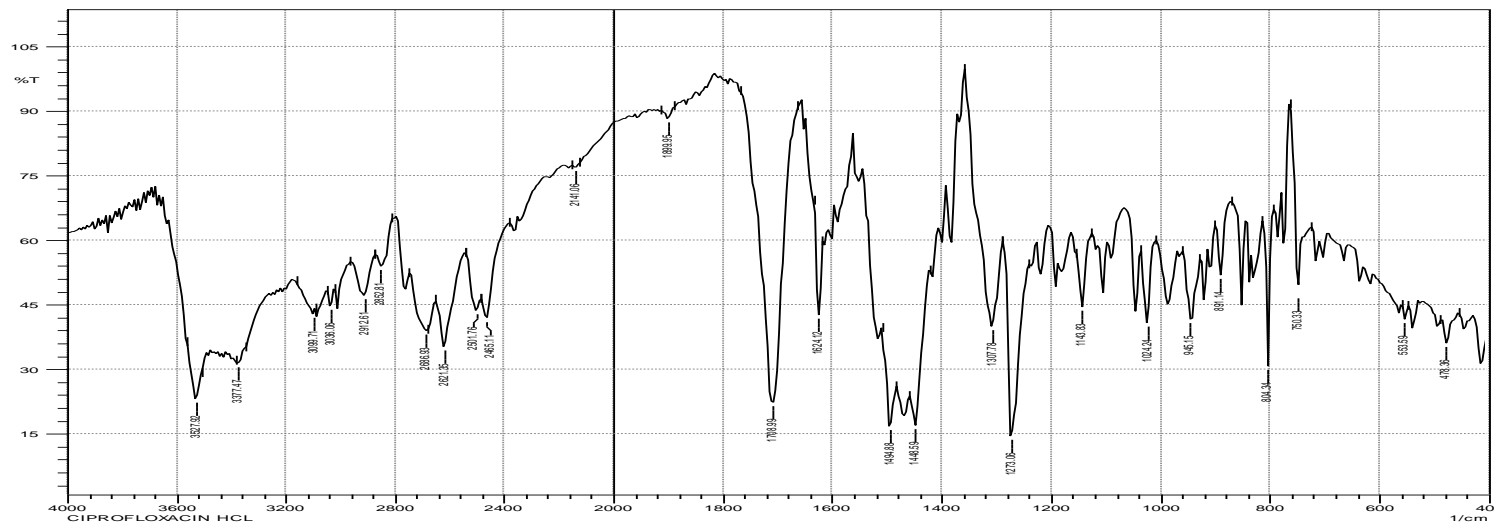

Figure 3: FTIR-Spectra of Ciprofloxacin hydrochloride with Acrycoat L100 


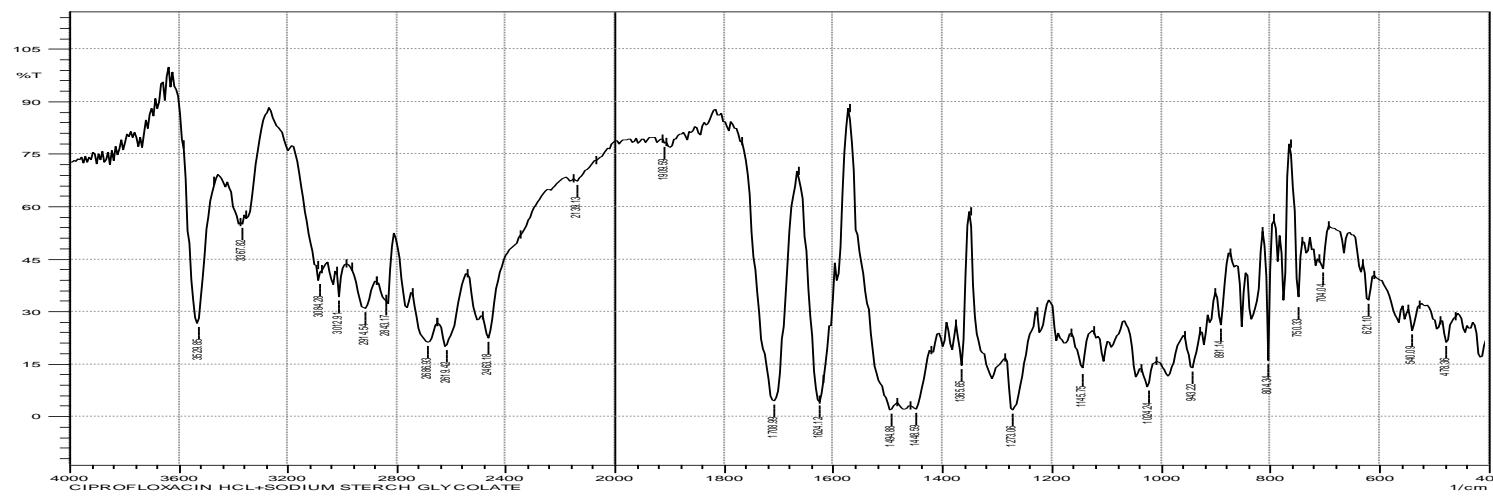

Figure 4: FTIR-Spectra of Ciprofloxacin hydrochloride with Sodium starch glycolate

The release of ciprofloxacin hydrochloride from the prepared formulations was analyzed by different release kinetics model as shown in figure 5 to figure 9. Simple visual observation of the plot shows an initial burst effect. From all the formulations, near $30 \%$ of the ciprofloxacin hydrochloride was released within the first 15 minutes of the dissolution study. This initial high amount of ciprofloxacin hydrochloride release can be attributed to the immediate release layer of the formulations.

In the formulations F1, F2, F3, as the proportion of the ethyl cellulose increases, the release rate of the drug decreases. Formulation F1 could not sustain the release beyond 7 hours where drug and EC was in a ratio of 1:0.5, whereas other formulations like F2 and F3 where drug and EC ratios were 1:1 and 1:1.5 respectively have shown the desired release profile over the test period of 10 hours. Therefore, formulation F2 was selected as the optimized formulation keeping in view that this formulation involves minimum amount of ethyl cellulose required to sustain the release of the contained drug for a period of 10 hours. It has been evidence that the formulation F2 was obeying the Higuchi release pattern with the $\mathrm{R}^{2}$ value of 0.9539 ). For further confirmation of the drug release mechanism, results of the in-vitro dissolution data were fitted to the KorsmeyerPeppas kinetics model. The value of the release exponent (n) for the optimized formulation F2 was found to be 0.3756 indicating the release governed by Fickian diffusion. Similarly, formulations containing acrycoat L100 and acrycoat S100 were also examined to check their ability to sustain the drug release pattern. Formulations F4 and
F5,where drug and acrycoat L100 was in a ratio of 1:0.5 and 1:1 respectively and formulations $\mathrm{F} 7$ and F8, where drug and acrycoat S100 ratio was $1: 0.5$ and $1: 1$ respectively were found to release maximum of the contained drug well before 12 hours i,e; within 10 hours. However, the formulation F6 and F9 where the drug was combined with acrycoat L100 and acrycoat S100 in a ratio of 1:1.5 each was found to sustain the release of the drug well above 12 hours since minimum drug release occurred within 10 hours from both the formulations. Hence, formulation F6 and F9 were selected as the optimized formulations. It has been evidence that the drug release from these formulations was obeying the Higuchi release pattern with the $\mathrm{R}^{2}$ value of $0.9545 \mathrm{and}$ 0.9510 respectively. The Korsmeyer-Peppas release (Figure 5) exponent (n) for the formulation F6 and F9 was found to be 0.394 and 0.397 , indicating release governed by the Fickian diffusion.

The shape factor ' $b$ ' as a Weibull function was determined for each of the formulations (Figure 6). Complex release mechanism i.e., the rate of release increases up to the inflection point and there after declines is seen if the $b$ value is more than 1. It has been found that for all the formulations, b values were ranging in between 0.39 to 0.69 which clearly indicate that diffusion in fractional or disorder substrate and different from the percolation cluster. Almost all the formulations prepared with ethyl cellulose, acrycoat L100 and acrycoat S100 have found to be predominantly obeying the Higuchi kinetics, Zero order kinetics and Fickian diffusion in their drug release behavior after the initial burst release.

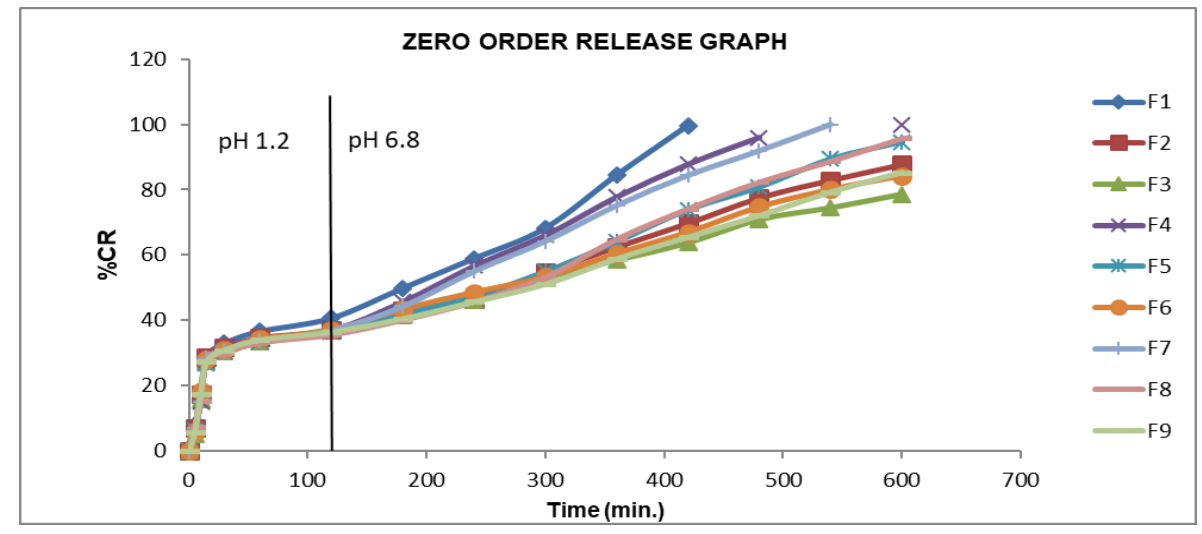

Figure 5: Zero order release profile of all formulations 


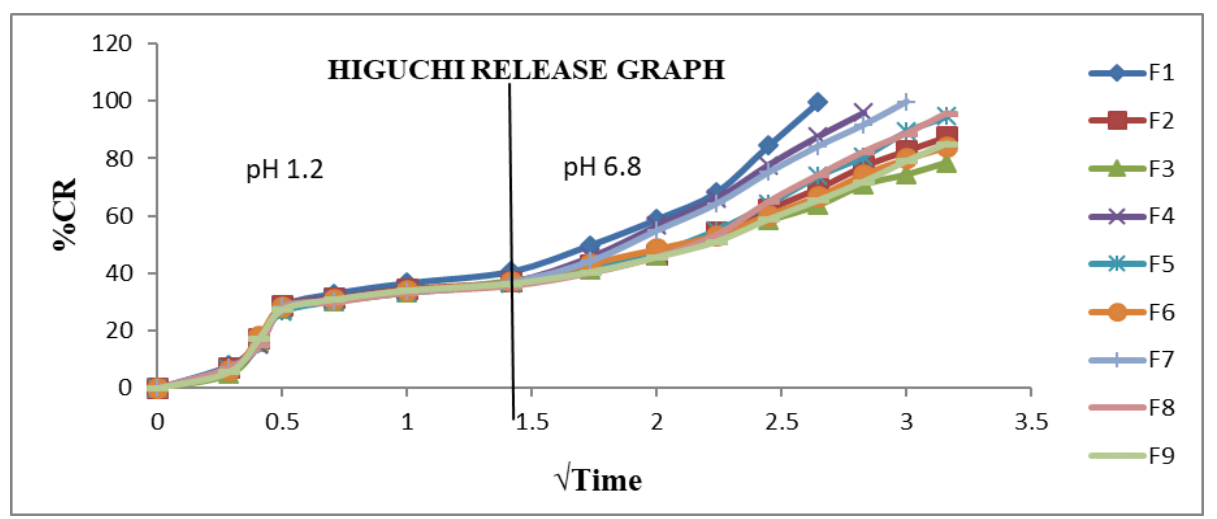

Figure 6: Higuchi release profile of all formulations

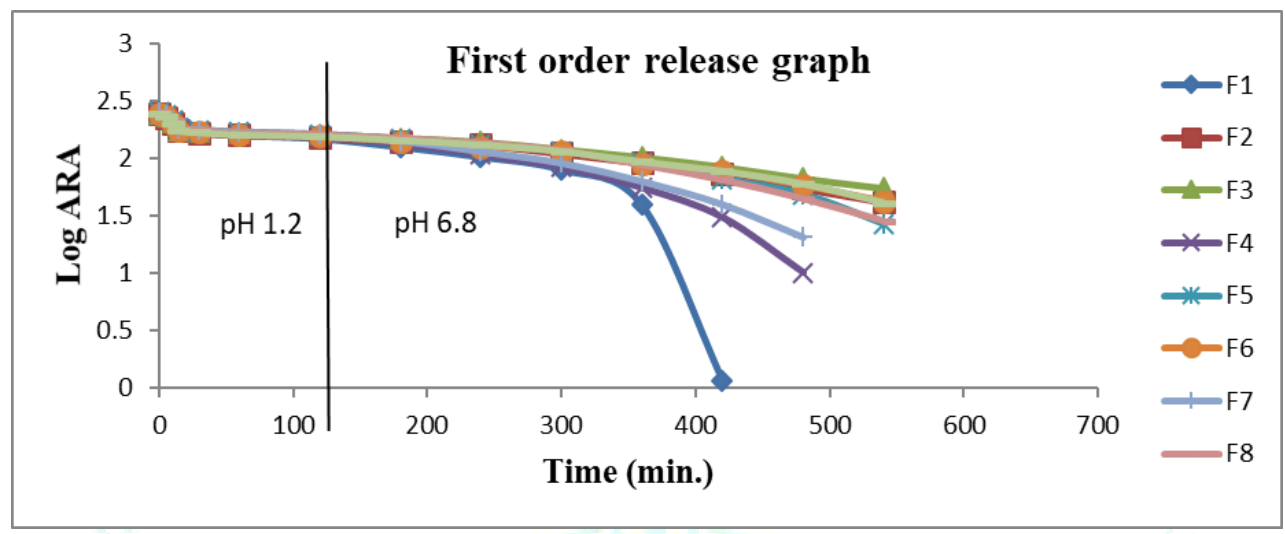

Figure 7: First order release profile of all formulations

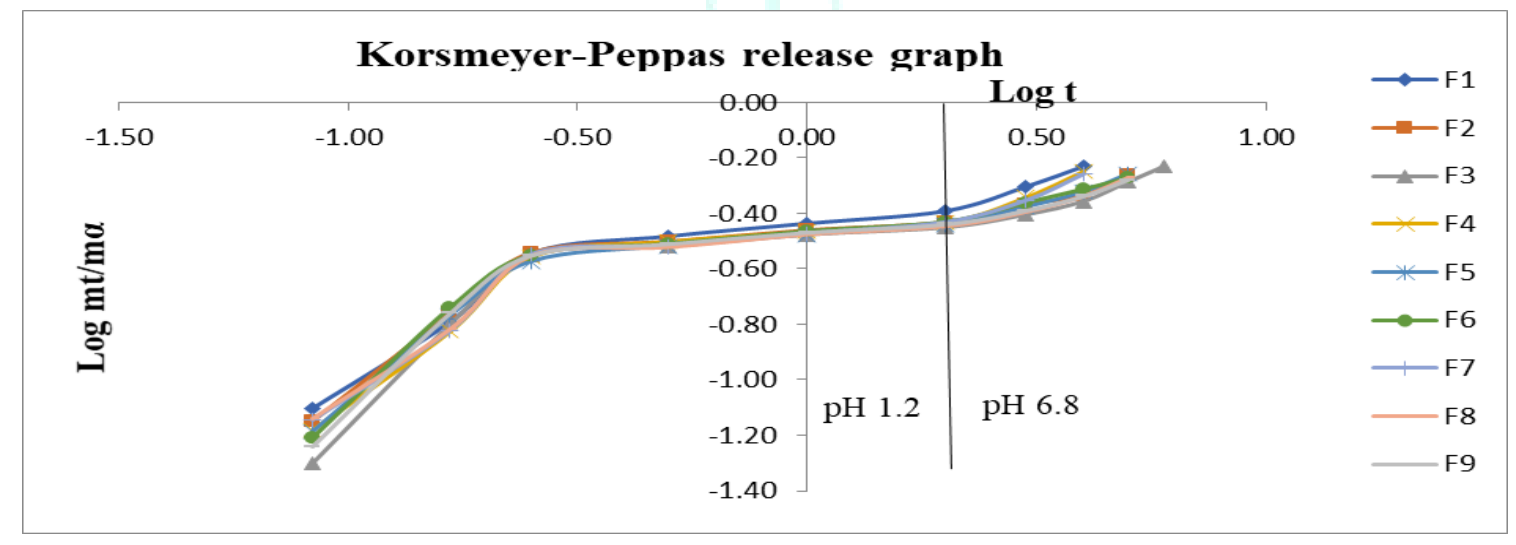

Figure 8: Korsmeyer-Peppas release profile of all formulations

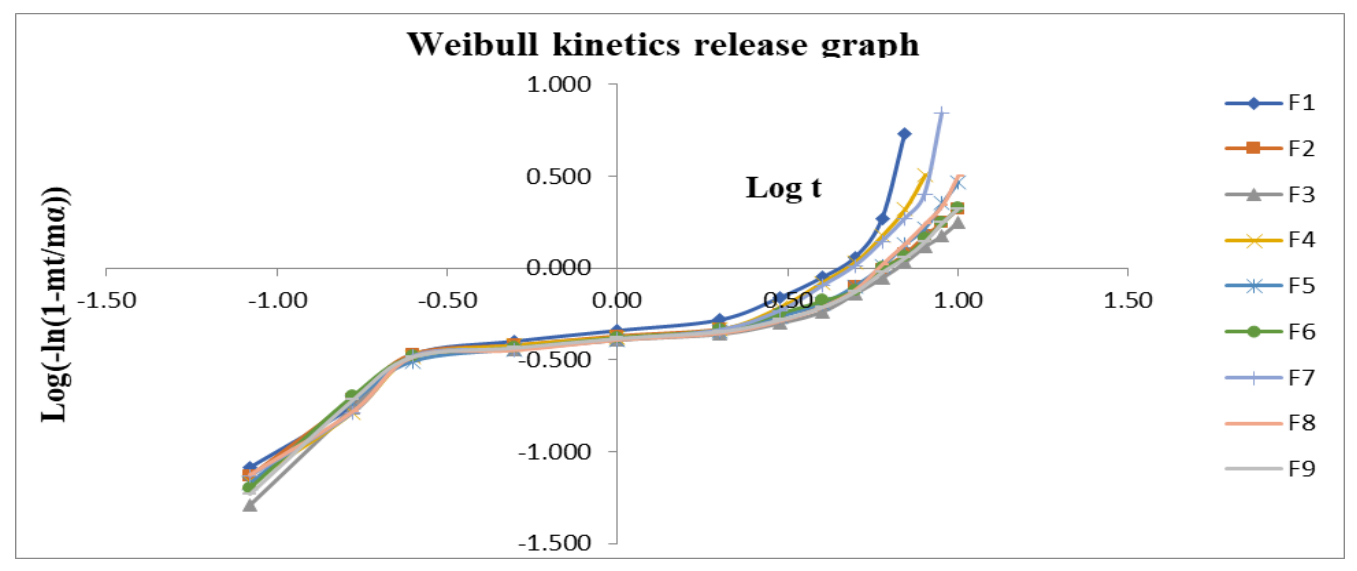

Figure 9: Weibull kinetics release profile of all formulations 
Statistical analysis (using one-way ANOVA analysis) has been showed that no significant difference occurred in the amount of drug release after the first 15 minutes from the optimized formulations shown in table 5 , since the $\mathrm{p}$ value is 0.8633.So it is evident that the initial burst of the fast release layer takes place from almost all the formulations irrespective of the polymer contents in them. Statistical analysis (using one-way ANOVA analysis) has shown that extremely significant difference occurred in the amount of drug release after the $10^{\text {th }}$ hours from the optimized formulations shown in table 8 , as the $p$ value is $<0.0001$. So it is evident that the incorporation of different polymers in different ratios for sustaining the release of the contained drug resulted in the variation in the observations.

Table 5: Summary of data at the first 15 mints (optimized formulations F2, F6 and F9).

\begin{tabular}{|l|c|c|c|c|}
\hline \multirow{2}{*}{ Group } & Minimum & Maximum & \multicolumn{2}{c}{ 95\% Confidence Interval } \\
\cline { 4 - 5 } \multicolumn{1}{l}{} & & & From \\
\hline Column A & 28.099 & 28.780 & 27.533 & 29.263 \\
\hline Column B & 27.999 & 28.824 & 27.200 & 29.423 \\
\hline Column C & 27.4076 & 28.678 & 27.188 & 29.245 \\
\hline
\end{tabular}

Table 6: Intermediate calculations of drug release at 15 minute using one-way ANOVA

\begin{tabular}{|c|c|c|c|}
\hline Source of variation & Degrees of freedom & Sum of squares & Mean square \\
\hline Treatments (between columns) & 2 & 0.04949 & 0.02475 \\
\hline Residuals (within columns) & 6 & 0.9859 & 0.1643 \\
\hline Total & 8 & 1.035 & \\
\hline \multicolumn{4}{|c|}{$F=0.1506=\left(M_{\text {Streatment }} / M_{\text {Sresidual }}\right)$} \\
\hline
\end{tabular}

\begin{tabular}{|c|c|c|c|c|c|}
\hline Group & $\begin{array}{c}\text { Number of } \\
\text { points }\end{array}$ & Standard mean & Standard Error of Deviation & Mean & Median \\
\hline Column A & 3 & 28.398 & 0.3482 & 0.2010 & 28.314 \\
\hline Column B & 3 & 28.312 & 0.4475 & 0.2584 & 28.112 \\
\hline Column C & 3 & 28.216 & 0.4140 & 0.2390 & 28.091 \\
\hline
\end{tabular}

Table 7: Summary of data at $10^{\text {th }}$ hour (optimized formulations F2, F6 and F9).

\begin{tabular}{|l|c|c|c|c|}
\hline \multirow{2}{*}{ Group } & Minimum & Maximum & \multicolumn{2}{c}{ 95\% Confidence Interval } \\
\cline { 4 - 5 } \multicolumn{2}{c|}{} & & From & To \\
\hline Column A & 87.989 & 88.879 & 87.317 & 89.531 \\
\hline Column B & 83.981 & 84.743 & 83.342 & 86.283 \\
\hline Column C & 84.904 & 85.893 & 84.203 & 86.733 \\
\hline
\end{tabular}

Table 8: Intermediate calculations of drug release at 10 hour using one way ANOVA.

\begin{tabular}{|c|c|c|c|}
\hline $\begin{array}{l}\text { Source of variation } \\
\end{array}$ & Degrees of freedom & Sum of squares & Mean square \\
\hline Treatments (between columns) & 2 & 26.978 & 13.489 \\
\hline Residuals (within columns) & 6 & 1.221 & 0.2034 \\
\hline Total & 8 & 28.199 & \\
\hline
\end{tabular}

\begin{tabular}{|c|ccc|c|c|}
\hline Group & $\begin{array}{c}\text { Number of } \\
\text { points }\end{array}$ & Standard mean & $\begin{array}{c}\text { Standard Error } \\
\text { of Deviation }\end{array}$ & Mean & Median \\
\hline Column A & 3 & 88.424 & 0.4454 & 0.2572 & 88.404 \\
\hline Column B & 3 & 84.312 & 0.3906 & 0.2255 & 84.213 \\
\hline Column C & 3 & 85.468 & 0.5092 & 0.2940 & 85.608 \\
\hline
\end{tabular}

(Values are given in mean \pm SD, $n=3$ )

Table 9: Tukey-Kramer multiple comparisons test.

\begin{tabular}{|c|c|c|c|}
\hline Comparison & Mean difference & $\mathbf{q}$ & P value \\
\hline Column A vs. Column B & 4.112 & 15.790 & $* * * \mathrm{P}<0.001$ \\
\hline Column A vs. Column C & 15.790 & 11.351 & $* * * \mathrm{P}<0.001$ \\
\hline Column B vs. Column C & -1.156 & 4.438 & $* \quad \mathrm{P}<0.05$ \\
\hline
\end{tabular}




\section{CONCLUSION}

The objective of the proposed work was to develop a Novel Drug Delivery System (NDDS) in the form of orally administered fast and slow releasing bilayer tablet containing Ciprofloxacin Hydrochloride. Polymers like ethyl cellulose, acrycoat L100 and acrycoat S100 in different ratios have been examined for matrix forming properties to regulate the release of contained drug. Proposed work was aimed at the delivery of the drug throughout a time span of up to 10 hours. Detailed investigation on the present topic has certainly added a newer dimension towards the controlled release of ciprofloxacin hydrochloride.

Present research work involve the development of a bilayer tablet of ciprofloxacin hydrochloride using a superdisintegranting agent (sodium starch glycolate) for the fast releasing layer and hydrophobic polymers like ethyl cellulose, acrycoat L100 and acrycoat S100 for the delayed releasing layer. There was the initial burst effect from the formulations to provide the loading dose of the drug, followed by sustained release to provide maintenance dose of the drug. Ciprofloxacin hydrochloride bilayer tablets were found promising and as potential alternative to the conventional dosage form of the drug.

\section{REFERENCES}

1. Ochoa L, Pedraz J.L. Preparation of sustained release hydrophilic matrices by melt granulation in a high shear mixer. Journal of Pharmacy \& Pharmaceutical Science, 2005; 8:13240.

2. Rahman Z, Ali M and Khar R K. Design and evaluation of bilayer floating tablets of captopril. Acta Pharmaceutica, 2006; 56:4957.
3. Libermann H.A, Lachman L, Kanig J.L. The Theory and Practice of Industrial Pharmacy, Indian 3rd Ed., Bombay; Varghese Publishing house: 1987.

4. Foster, Rachel H, Keam, Susan J. Prolonged Release Ciprofloxacin. American Journal of Drug Delivery, 2006; 4:11320.

5. Upadrashta S.M, Katikaneni P.R, Hileman G.A and Keshary P.R. Direct compression controlled release tablets using ethyl cellulose matrices. Drug Development and Industrial Pharmacy, 1993; 19:449- 60.

6. Chinam N.P, Arethi B.K, Hemant K.P, Satya P.S, Medhuri V.D., Design and evaluation of Sustained release bilayer tablets of Propanolol Hydrochloride. Acta Pharmaceutica, 2007; 57:47989.

7. Indurwade N.H, Rajyagures T.H, Halith S.M, Pillai K.K, Balasubhramaniyam P, Nakhat PD. Formulation and evaluation of bilayer tablets of amlodipine besilate and metprolol succinate. Indian Drug, 2002; 39(8):405-09.

8. Guyot M, Fawaz F. Nifedipine loaded polymeric microspheres: preparation and physical characteristics. International Journal of Pharmaceutics, 1998; 175:61-74.

9. Remya P.N, Damodharan N, Sulakshan K.C.V. Formulation and Evaluation of bilayered tablets of Ibuprofen and Methocarbamol. International Journal of Pharm Tech Research, 2010; 2(2):1250 - 55.

10. Patel H.P, Patel N.J. Formulation and Evaluation of Biphasic Drug Delivery System of Diclofenac Sodium using Compressed Mini Tablet. International Journal of Pharma. Research \& Development, 2009; 3:76-82.

11. Shirse P. Formulation and Evaluation of Bilayer Tablets of Diclofenec Sodium with Ranitidine HCL for Susteained and Immediate Release. Journal of Applied Pharmaceutical Sciences, 2012; 02(5):136-41.

12. Statistical Analysis 8: Two Way Analysis of Variance (ANOVA), Compliation prepared by Center for Excellence, Sigma, http://www.statstutor.ac.uk/resources/uploaded/coventrytw owayanova.pdf. 